\title{
A Variant Articular Facet on Left Second Rib
}

\section{Simmi Mehra}

\begin{abstract}
During routine scanning of bones in the Department of Anatomy, Mahatma Gandhi Medical College \& Hospital, Jaipur, India, an unusual second rib belonging to left side was found having an oval facet, almost centrally placed along the inner border of the shaft. In the absence of the corresponding skeleton, it can be hypothesized that the left first rib or an extra rib articulated with the second rib at this facet. Such structural anomalies of ribs are quite rare and need to be documented. If present, they may lead to compression of neurovascular structures crossing the ribs leading to thoracic outlet syndrome. An incidence of $0.3 \%$ of synostosis of first and second ribs has been reported in the literature. Search of literature reveals that there are 22 known syndromes in which fused ribs are a constant component. Such a variant second rib as found in the present case could lead to neurovascular compression and a possible indicator of underlying systemic disorder.
\end{abstract}

Keywords: Bicipital rib, Fused second rib, Synostosis of ribs, Thoracic outlet syndrome.

How to cite this article: Mehra S. A Variant Articular Facet on Left Second Rib. J Mahatma Gandhi Univ Med Sci Tech 2017;2(1):29-30.

\section{Source of support: Nil}

\section{Conflict of interest: None}

\section{INTRODUCTION}

Variants of first and second ribs are rare anatomical findings. Such variants are discovered as incidental findings on routine chest radiographs or as part of systemic disorders or syndromes like Poland syndrome, Klippel-Feil syndrome, Jarco-Levine syndrome, and Gorlin syndrome. ${ }^{1}$ These anomalies usually are fused cervical rib and first rib, or fusion between first and second ribs. These can lead to compression of structures arching over the first rib, viz., lower trunk of brachial plexus and subclavian vessels and presenting as thoracic outlet syndrome (TOS). ${ }^{2-5}$ Incidence of fused first and second ribs has been reported to be $0.3 \%$ in a study based on chest

\section{Professor and Head \\ Department of Anatomy, Mahatma Gandhi Medical College \& Hospital, Jaipur, Rajasthan, India}

Corresponding Author: Simmi Mehra, 403, Madho Pearl Pride Apts., 6, Vivekananda Marg, C-Scheme, Jaipur-302001 Rajasthan, India, Phone: +919929399941, e-mail: docsims27 july@gmail.com radiographs. ${ }^{6}$ The present report of a variant facet on the inner border of left second rib is an attempt to add to the various anomalies reported in the literature and to lay emphasis on the possible embryological explanation and clinical implications of such findings.

\section{CASE REPORT}

During routine sorting of ribs in the osteology lab in the Department of Anatomy, Mahatma Gandhi Medical College \& Hospital, Jaipur, India, a left second rib was found displaying an anomalous facet almost in the middle of the inner border opposite the rough impression meant for attachment of serratus anterior muscle (Fig. 1).

The rib was identified as the second rib by the presence of divided articular facet at the head, flat shaft with convex external surface and a centrally placed rough impression superolaterally, neck and two tubercles. The smooth and concave internal surface facing inferomedially displayed a short costal groove in posterior part (Fig. 2). The variant oval facet measured $16 \mathrm{~mm}$ along its long axis. The width varied as it was narrow anteriorly $(4 \mathrm{~mm})$ and broader posteriorly $(9 \mathrm{~mm})$. The facet was located at a distance of $7.8 \mathrm{~cm}$ (inner border) from the anterior end of the rib. The total length of the rib (measured with thread and scale) at the outer border was $19.3 \mathrm{~cm}$. The width of the rib at the level of the facet was $2.8 \mathrm{~cm}$ and the width of the rib both anterior and posterior to the facet measured 2.0 and $1.5 \mathrm{~cm}$ respectively.

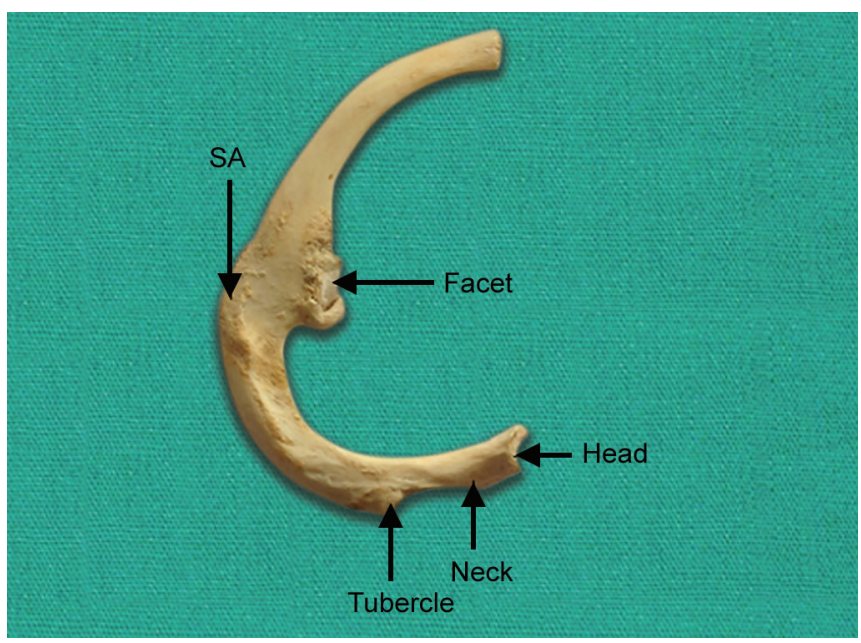

Fig. 1: Left second rib superior surface showing head, neck, tubercle, variant facet on inner border. SA: rough impression for serratus anterior muscle attachment 


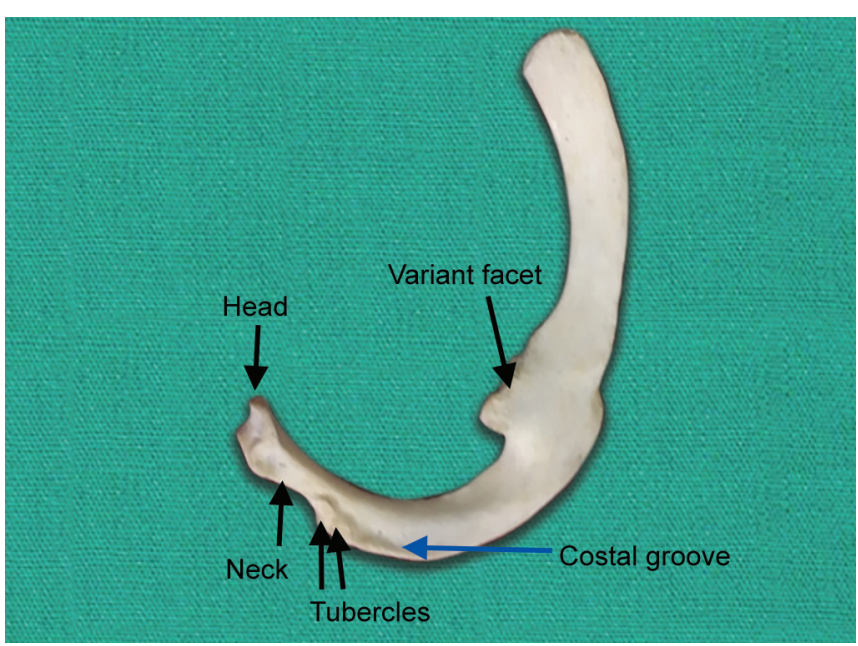

Fig. 2: Inferior surface of left second rib showing head, neck, tubercles, costal groove (blue arrow), variant facet

\section{DISCUSSION}

Embryological explanation of rib variants at the upper end of thoracic cage is due to errors in segmentation of axial skeleton before the 20th day of development. This has been attributed to malexpression of various myogenic determinants like Myogenin, MyoD, MRF4, and Myf5. ${ }^{2}$ The variations in arterial tree have been known to affect development of upper ribs on the left side. ${ }^{7}$

Rib defects of congenital origin have been classified into two types, viz., numerical and structural. Numerical defects include: (a) Supernumerary ribs, such as cervical, lumbar, sacral, or pelvic ribs; and (b) deficient pairs, such as 11 pairs seen in Down's syndrome. The structural variants are quite rare and include short rib, bifid or forked rib, fused (synostosis) or bridged ribs, bicipital ribs, and pseudoarthrosis of first rib. ${ }^{8}$ The present case can be classified under the structural variant type. Congenitally abnormal first rib and associated second rib synostosis has been reported by many researchers in the past. ${ }^{9-14}$ In the present case, with the absence of corresponding ribs of the same skeleton, one can simply hypothecate that the left first rib articulated with the left second rib at the variant facet with its head end, which bears a single facet, instead of the vertebral body. This could have led to higher arching of the left thoracic inlet, which in turn could have caused overstretching of lower trunk of brachial plexus and subclavian vessels at the level of the facet, since the shaft was broadest here leading to symptoms of TOS. Such first rib fusion malformations are commonly associated with postfixed brachial plexus with greater contribution from second thoracic nerve. Congenital anomalies of first rib lead to sagging of shoulder girdle, which leads to traction on the lower trunk of brachial plexus causing neurological symptoms. ${ }^{10,15}$ Fusion of ribs often leads to curvature of spine toward the area of fused ribs leading to impaired lung growth and a condition called Thoracic Insufficiency Syndrome. ${ }^{10}$

The clinical history and corresponding skeleton being unavailable, one can only speculate as to the articulations at the variant facet, clinical implications like TOS, scoliosis, or some underlying systemic disorder/syndrome. These findings are of interest not only to anatomists but also to radiologists, thoracic surgeons, and clinicians.

\section{REFERENCES}

1. Winter, RM.; Baraister, M.; Multiple congenital anomalies. A diagnostic compendium. 1st ed. London: Chapman and Hall Medical; 1991. p. 1263-1264.

2. White JC, Poppel MH, Adams R. Congenital malformations of the first thoracic rib: a cause of brachial neuralgia which stimulates the cervical rib syndrome. Surg Gynecol Obstet 1945 Dec;81:643-659.

3. Baumgartner F, Nelson RJ, Robertson JM. The rudimentary first rib. A cause of thoracic outlet syndrome with arterial compromise. Arch Surg 1989 Sep;124(9):1090-1092.

4. Hashimoto H, Nikaido Y, Nagai S, Shimado K. A case report of thoracic outlet syndrome with acute arterial obstruction caused by abnormal first rib. Nihon Kyobu Geka Gakkai Zasshi 1997 Dec;45(12):2026-2029.

5. Atosy E. Thoracic outlet syndrome: anatomy. Hand Clin 2004;20:7-14.

6. Etter LE. Osseous abnormalities in thoracic cage seen in forty thousand consecutive chest photoroentogenograms. Am J Roentogenol 1944;51:359-383.

7. Todd TW. Costal anomalies of the thoracic inlet, interpretation and significance. Anal Anz 1912;41:257-271.

8. Rani A, Rani A, Chopra J, Manik P. Synostosis of first and second rib - case report. J Anat Soc India 2009;58(2): 189-191.

9. Gupta V, Suri RK, Rath G, Loh H. Synostosis of first and second thoracic ribs: anatomical and radiological assessment. IJAV 2009;2:131-133.

10. Deepak S, Dakshayani KR. An unusual case of a bicipital rib - a report. Anatomica Karnataka 2011;5(1):50-52.

11. Anupama K, Prathap KJ, Radhika PM. An unusual case of synostosis of first and second rib. Int J Anat Res 2013;1(2):104-106.

12. Lokanayaki V. Bicipital ribs - a report of four cases. Peoples J Sci Res 2013;6(2):51-54.

13. Joshi UU, Mudiraj NR. Case report of synostosis of first and second rib - a bridged variety. Int J Cur Res Rev 2014;6(6):55-57.

14. Sampada PK, Vinitha G, Mallikarjun M, Jayaprakash BR. A bicipital rib - a case report. IJBR 2014;5(6):437-438.

15. Stapford JS, Telford ED. Compression of the lower trunk of brachial plexus by a first dorsal rib with a note on surgical treatment. Br J Surg 1919;7(26):168-177. 